\title{
Monitoring and Risk Assessment of Selected Pesticide Congeners (PCBs) in Nile River Waters, Egypt
}

\author{
Hossam F. Nassar \\ Department of Environmental Sciences and Industrial Development, Faculty of Post \\ Graduate Studies for Advanced Sciences, Beni-Suef University, Egypt.
}

\begin{abstract}
D ISCHARGING of higher levels of persistent organic pollutant (POPs) including PCBs to the Nile River waters poses a great environmental impact and human hazardous risk. Therefore, this study was carried out to assess the concentration levels of selected PCB congeners and evaluate their health risk at three different areas along Nile River from South to North of Egypt. Collected samples were extracted and analyzed using (GC-Ms, Agilent). The detected total average concentration levels of selected ten PCB congeners along the three sampling sites Beni-suef(S1), Greater Cairo (S2) and Banha (S3) were ranged from 3.89 to 25.5 with an average of $16.51 \mu \mathrm{g} / \mathrm{L}, 5.51$ to 33.61 with an average of $20.75 \mu \mathrm{g} / \mathrm{L}$ and from 6.14 to 39.55 with an average of $27.01 \mu \mathrm{g} / \mathrm{L}$ at S1, S2 and S3, respectively. These concentrations were above the acceptable permissible limit set by USEPA for PCBs in drinking water $(0.5 \mu \mathrm{g} / \mathrm{L})$, indicating an important $\mathrm{PCB}$ pollution problem in the Nile River water and high possibility of human adverse health effects. Therefore, counter measures and laws enforcement should be applied to minimize the risk of PCBs in the Egyptian environment.
\end{abstract}

Keywords: Water pollution, POPs, PCBs, Nile River, Risk assessment.

\section{Introduction}

Persistent organic pollutants (POPs) are carbonbased compounds contains other substances like pesticides and polychlorinated biphenyls (PCBs). Besides, other generated by-products resulting from different human and natural activities as dioxins. PCBs were used over fifty years in African countries for controlling and preventing agricultural pests [1]. Many studies have shown that POPs considered as one of the most dangerous contaminants released to the environment. Due to its hazardous risk, several conventions have been adopted to enhance chemical management and safety purposes for minimizing the threatening impacts of such chemicals worldwide. Stockholm Convention on May 2001, concerned on reducing the release of 12 POPs coined the 'Dirty Dozen' through the United Nations Environment Program (UNEP). These pollutants are highly Persistence in all environmental compartments like air, water and soils. The major problems of such pollutants were related to their ubiquitous distribution in the environment, the eventual penetration into food chains and bio-accumulation in human bodies causing several health problems as hormone disruptors that can affect the function of endocrine and reproductive systems in humans and wildlife. PCB congeners represent an important sector of POPs, which are believed to be possible carcinogens are extensively used in African countries, since more than 50 years for controlling agricultural pests and disease vectors like malaria [2].

Since, Egypt is one of the most intensive pesticide using countries, Nile River as the main water source became loaded with different types of POPs especially PCBs [3]. Nile River ecosystem has a particular interest since it provides drinking water for more than 95 million of populations and considered as the main source of irrigation. PCBs are widely distributed in the Egyptian environment as they have been used in a different manufacturing process particularly in insulators and plasticizers facilities [4]. PCB congeners reach water bodies via several routs like run-off and/or atmospheric transport. PCBs have a strong bioaccumulation potentiality across the food chain and contaminated water consumption [5]. 
POPs assessment and monitoring in water system have been well studied all over the world [6, N7, N8]. Whereas, in Egypt there is a deficiency of the studies related to freshwater aquatic environments and Nile River organic pollutants particularly pesticides data $[9,10$, N11]. So, the current study is to assess the actual concentration levels of ten selected PCB congeners (C28, C44, C52, C70, $\mathrm{C} 101, \mathrm{C} 105, \mathrm{C} 118, \mathrm{C} 138, \mathrm{C} 153$ and $\mathrm{C} 180)$ in Nile River as an important source of information showing the current state of water pollution in Egypt (Table1).

TABLE 1. Chemical structure and IUPAC names of the selected PCB congeners.

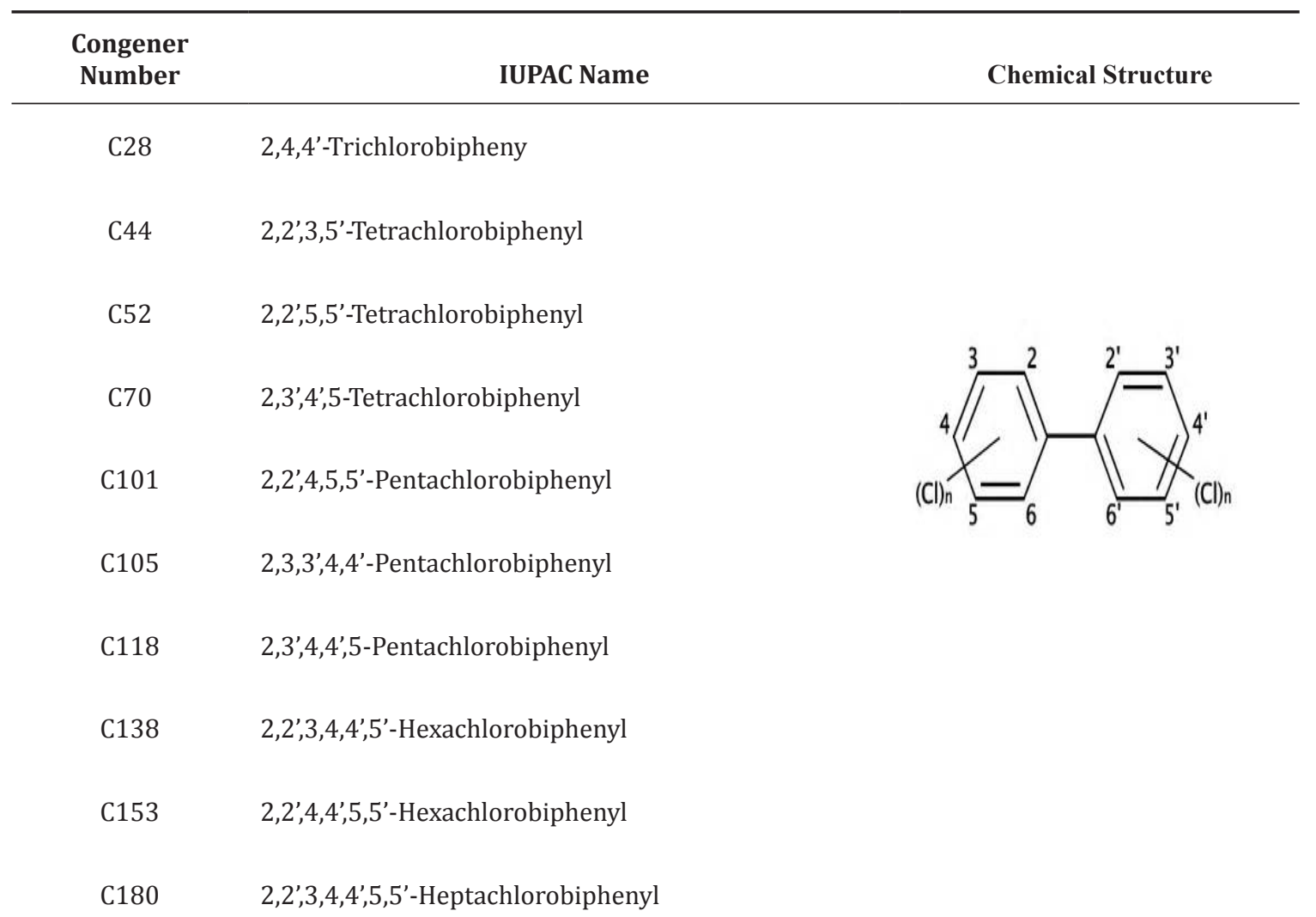

\section{Experimental}

Sampling and study area

Water samples were collected using $2.5 \mathrm{~L}$ amber glass bottle at depth around $30 \mathrm{~cm}$ below water surface from three sampling points along Nile River from south to north including Greater Cairo to represent the different activities around the Nile. Samples were collected on basis of 12 samples per each site during summer season of 2015.

(i) Beni-Suef area (S1), this site located at the south part of Nile River at a distance of $120 \mathrm{~km}$ from Cairo, this site characterized by receiving mixed contaminants from the industrial zone and agricultural drains.

(ii) Greater Cairo (S2), this site very close to the capital at Shubra Alkhema district in which many industrial facilities are found as (textile, food, glass, pipes and others.....).

(iii)Banha (S3), it is located at the north part of Egypt in the beginning of Delta region at a distance about $100 \mathrm{~km}$ from Cairo characterized by large areas of agricultural lands and consequently heavily loaded agricultural drains.

Chemicals, extraction and clean up

Chemicals and reagents including solvents as dichloromethane, acetonitrile, n-hexane and ethanol were purchased from Sigma and Alliance Bio, USA and El Nasr Pharmaceutical Chemical Co, Egypt as pesticide residue (PR) grade. Other chemical and reagents were provided by the National Research 
Center, Egypt.

All samples were extracted twice using liquidliquid extraction method according to APHA [12]. Then the extracts were combined, dried and concentrated to about $1 \mathrm{~mL}$ in a rotary evaporator.

\section{Clean up}

Clean up and fractionation of the extracted samples were carried out with pouring about 20 $\mathrm{g}$ of $0.5 \%$ activated florisil to column. The first fraction can be obtained by eluting the column with $60 \mathrm{~mL}$ of $30 \%$ ethylene chloride in n-hexane. Whereas, the second fraction can be achieved by the gradient elution of dichloromethane in hexane with $35 \mathrm{~mL}$ of $30 \%$ and $45 \mathrm{ml}$ of $50 \%$, respectively. Finally, concentrate each fraction via rotary evaporator until reach the volume of 2-3 $\mathrm{mL}$ [13].

\section{Instrumentation}

Quantitative analysis of the extracted samples was carried out using gas chromatograph with mass spectra (GC-Ms, Agilent, Folsom, CA ) operated in a splitless mode. The florisil column capillary of $30 \mathrm{~m}$ length $\times 0.25 \mathrm{~mm}$ internal diameter $\times 0.25 \mu \mathrm{m}$ film thickness, Agilent). The column temperatures were set initially at $180{ }^{\circ} \mathrm{C}$ for $2 \mathrm{~min}$, then raised to $220^{\circ} \mathrm{C}$ for $1 \mathrm{~min}$, finally raised to $280{ }^{\circ} \mathrm{C}$ for $30 \mathrm{~min}$. Nitrogen gas was used as a carrier gas at flow rate of $4 \mathrm{~mL} / \mathrm{min}$. All the instrumental conditions were reported in Khaled et al. [14]. The limit of detection (LOD) of PCBs was determined by the ratio of signal to noise $(\mathrm{S} / \mathrm{N})$. The analyzed samples showed recoveries of $\mathrm{PCB}$ congeners ranged between 79.3 and $95.8 \%$.

\section{Risk assessment}

According to the risk guidelines of USEPA [15], the cancer risk assessment of PCB congeners via water consumption was calculated using equation the of:

$$
\text { Cancer Risk }=\frac{C \times D I \times E D}{B W \times A T} \times C S F \times C F
$$

where, $\mathrm{C}$ is the concentrations of PCBs in water sample (ng L $\left.{ }^{-1}\right)$; DI is the daily input ( $\mathrm{L}$ day -1$)$ : $2 \mathrm{~L} \mathrm{day}^{-1}$; ED is the exposure duration (year): 30 years; BW is body weight $(\mathrm{kg}): 60 \mathrm{~kg}$; AT is average life span (year): 70 years; CSF is the cancer slope factor $(\mathrm{mg} / \mathrm{kg} / \text { day })^{-1}: 0.07(\mathrm{mg} / \mathrm{kg} /$ day); and CF is the conversion factor: $10^{-6}$.

\section{$\underline{\text { Results and Discussion }}$}

$P C B$ levels in river water

The detected PCB congeners are evaluated with and its distribution in Nile River water from the designed sampling points along three different governorates Beni-Suef (S1), Greater Cairo (S2) and Banha (S3) as shown in Table 2. PCB congener's average concentrations showed significant variations between each sampling region. In Beni-Suef region (S1) the highest detected concentration of PCB congeners was for $\mathrm{C} 138$ that varied from 1.12 to $8.32 \mu \mathrm{g} / \mathrm{L}$ with an average concentration of $5.5 \mu \mathrm{g} / \mathrm{L}$ followed by $\mathrm{C} 44$ with an average concentration of $2.34 \mu \mathrm{g} / \mathrm{L}$. C44 showed the highest concentration level in Greater Cairo (S2) region that varies from 1.6 to $5.8 \mu \mathrm{g} / \mathrm{L}$ with an average concentration of 4.3 followed by $\mathrm{C} 101$ with average concentration of $2.4 \mu \mathrm{g} / \mathrm{L}$. For the third region Banha (S3) C153 showed the higher concentration levels that vary from 1.6 to $7.8 \mu \mathrm{g} / \mathrm{L}$ with an average concentration of $5.2 \mu \mathrm{g} / \mathrm{L}$ followed by $\mathrm{C} 44$ with an average concentration of $4.9 \mu \mathrm{g} / \mathrm{L}$. Among all sampling sites S3 showed the highest detected concentrations varied from 6.1 to $39.5 \mu \mathrm{g} / \mathrm{L}$ with an average concentration of $27.01 \mu \mathrm{g} / \mathrm{L}$ followed by S2 and S1 with an average concentration levels of 20.7 and 16.5 $\mu \mathrm{g} / \mathrm{L}$, respectively. In addition, the percentage of total average concentrations of PCB congeners $(\mathrm{C} 28+\mathrm{C} 44+\mathrm{C} 52+\mathrm{C} 70+\mathrm{C} 101+\mathrm{C} 105+\mathrm{C} 118+$ $\mathrm{C} 138+\mathrm{C} 153+\mathrm{C} 180)$ at the three sampling sites (S1, S2 and S3) showed the highest percentage of $42 \%$ at S3 followed by $32 \%$ at S2 and $26 \%$ at $\mathrm{S} 1$ as shown in Fig. 1. These investigated high concentration levels at S3 of Banha governorate at Delta region were due to the predominance of agricultural activities that discharge huge amounts of contaminated water highly loaded with fertilizers and pesticides besides other facilities like soap production, detergents and pharmaceutical industries. These results were higher than those discussed by Megahed et al. [16] and Dahshan et al. [17]. Figure 2 shows the total average concentrations of each individual PCB congeners that followed the order of: $\mathrm{C} 44>$ $\mathrm{C} 138>\mathrm{C} 105>\mathrm{C} 153>\mathrm{C} 180>\mathrm{C} 28>\mathrm{C} 70>\mathrm{C} 101>$ C52> C118. Whereas the distribution levels of PCB congeners along the three sampling points (S1, S2 and S3) can be observed in Fig. 3, which showed the highest concentration levels of PCBs were detected at $\mathrm{S} 3$ followed by $\mathrm{S} 2$ and the lowest concentrations were detected at $\mathrm{S} 1$. This tendency $(\mathrm{S} 3>\mathrm{S} 2>\mathrm{S} 1)$ could be attributed to the 
accumulative effect of contaminants in upward stream pattern from south to north of Nile River. Moreover, the semi-volatile characteristics of PCBs enabling them to travel over long distances in the atmosphere then condensed and deposited at the most cooler temperature regions like Delta region in our case.

\section{Risk assessment}

Recently, Egypt's Nile River waters receive about 2.5 million $\mathrm{m}^{3}$ per day of untreated wastewater from more than 400 factories as an estimated number of facilities discharging there effluents to Nile River [18]. Accordingly, there is an increasing probability of hazardous risk to the aquatic-ecosystems due to the intensive exposure to multi-toxicants particularly organic pollutants as POPs including PCBs. Such compounds are mostly carcinogenic and or mutagenic pollutants.

Egypt water regulations have no specific criteria for the maximum allowed concentration limits of PCBs. Whereas; USEPA [19] set a permissible limit value for PCBs in drinking water to be $0.5 \mu \mathrm{g} \mathrm{\textrm {L } ^ { - 1 }}$. So, the investigated average concentrations levels of the selected PCB congeners at the three sampling sites along
Nile River were all above the designed values as shown in Table (2).

Moreover, cancer risk (CR) assessment of PCBs was calculated at the three selected regions (S1, S2, and S3) along the Nile River according to the following equation:

$$
\text { Cancer Risk }=\frac{C \times D I \times E D}{B W \times A T} \times C S F \times C F
$$

The calculated values of $\mathrm{CR}$ for the three sampling sites (S1, S2 and S3) were $0.016 \times$ $10^{-3}, 0.020 \times 10^{-3}$, and $0.027 \times 10^{-3}$, respectively. Since, the cancer risk permissible levels of PCBs contaminants in the aquatic environment were in $\left(10^{-4}-10^{-6}\right)$ [20]. All the mentioned results indicated that Nile River water is not safe enough and may pose a health risk to both human and aquatic environment.

\section{Conclusion}

The detected concentration levels and distribution pattern of PCB congeners along Nile River water indicated serious environmental impacts and human health risk effects as well. The spatial tendency of PCB congeners that follow $(\mathrm{S} 3>\mathrm{S} 2>\mathrm{S} 1)$ referred to the accumulative effect of contaminants in upward stream pattern

TABLE 2. Concentration values $(\mu \mathrm{g} / \mathrm{L})$ of selected PCB congeners at different sites along Nile River, Egypt.

\begin{tabular}{cccccccccccccc}
\hline PCB Congener & & \multicolumn{3}{c}{ S 1 } & \multicolumn{1}{c}{ S 2 } & & & S 3 \\
\hline$(\mu \mathrm{g} / \mathrm{l})$ & min & Max & ave & std & min & max & ave & std & min & max & ave & std \\
& & & & & & & & & & & & \\
C28 & 0.12 & 2.13 & 1.36 & 0.45 & 0 & 2.74 & 2.11 & 0.96 & 0.19 & 3.15 & 2.86 & 1.13 \\
C44 & 1.21 & 2.87 & 2.34 & 0.87 & 1.64 & 5.89 & 4.31 & 2.1 & 1.52 & 6.23 & 4.91 & 2.19 \\
C52 & 0 & 1.48 & 1.12 & 0.48 & 0.28 & 2.13 & 1.67 & 0.41 & 0.18 & 2.05 & 1.34 & 0.53 \\
C70 & 0.16 & 1.72 & 1.32 & 0.43 & 0.41 & 2.25 & 1.54 & 0.77 & 0.56 & 3.34 & 2.1 & 0.96 \\
C101 & 0.22 & 1.79 & 0.97 & 0.32 & 0.68 & 3.98 & 2.42 & 1.08 & 0 & 2.32 & 0.88 & 0.29 \\
C105 & 0.53 & 2.84 & 1.63 & 0.78 & 0.49 & 3.55 & 1.81 & 0.84 & 0.88 & 5.7 & 3.9 & 1.51 \\
C118 & 0 & 0.67 & 0.28 & 0.13 & 0.17 & 1.89 & 0.9 & 0.36 & 0 & 0.32 & 0.15 & 0.05 \\
C138 & 1.12 & 8.32 & 5.5 & 2.21 & 0.74 & 4.36 & 2.38 & 1.11 & 0.56 & 4.63 & 2.9 & 1.26 \\
C153 & 0 & 1.57 & 0.69 & 0.26 & 0.39 & 2.32 & 1.31 & 0.55 & 1.64 & 7.89 & 5.2 & 2.4 \\
C180 & 0.53 & 2.12 & 1.3 & 0.34 & 0.71 & 4.52 & 2.3 & 1.1 & 0.61 & 3.92 & 2.77 & 0.84 \\
\hline Total & 3.89 & 25.51 & 16.51 & 6.27 & 5.51 & 33.63 & 20.75 & 9.28 & 6.14 & 39.55 & 27.01 & 12.6 \\
\hline
\end{tabular}

Egypt.J.Chem. 60 , No.6 (2017) 


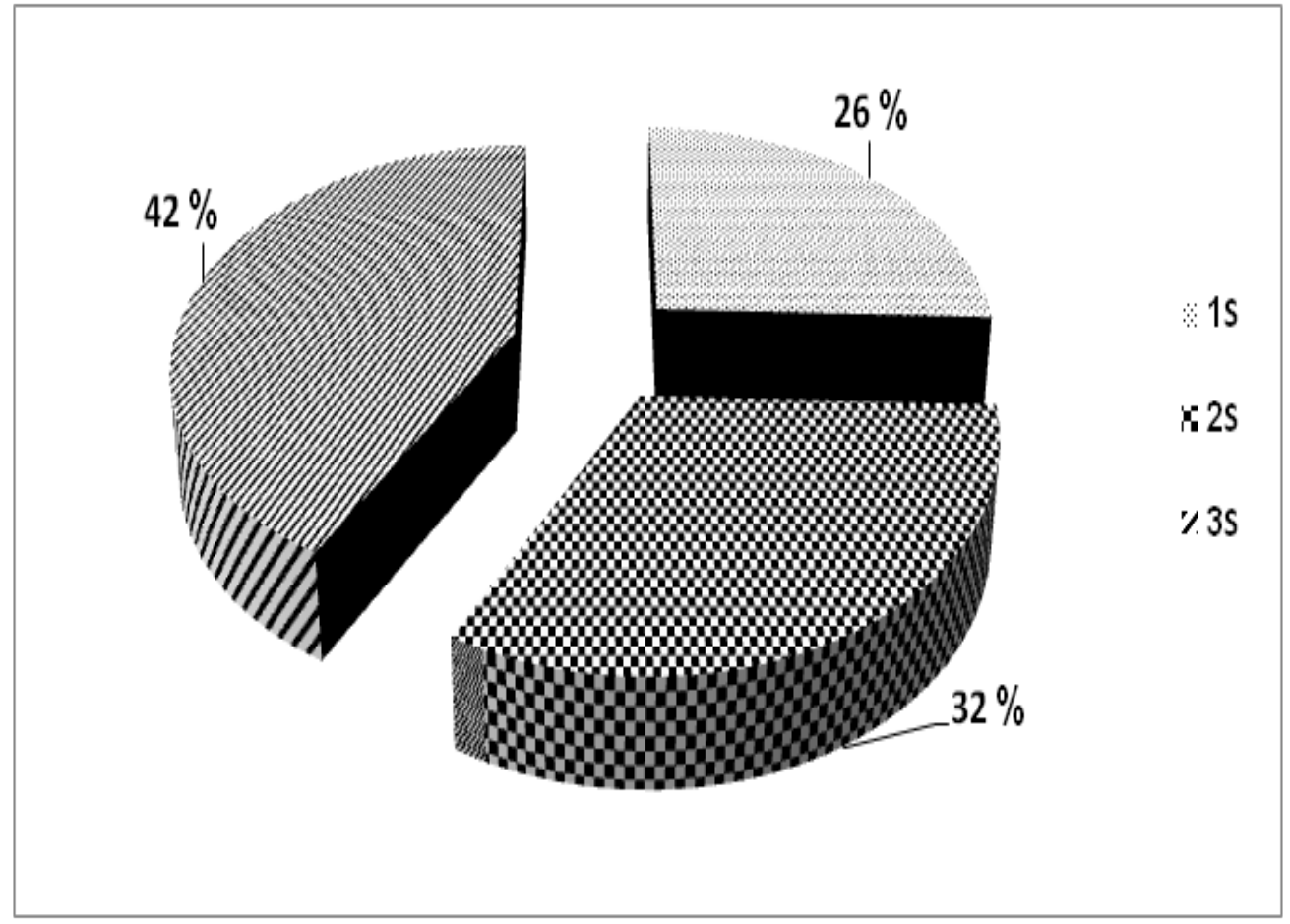

Total PCBs (= C28+C44+ C52+C70+C101+C105+C118+C138+C153+C180).

Fig. 1. Percentage of total average concentrations of PCB congeners along at the sampling sites along Nile River.

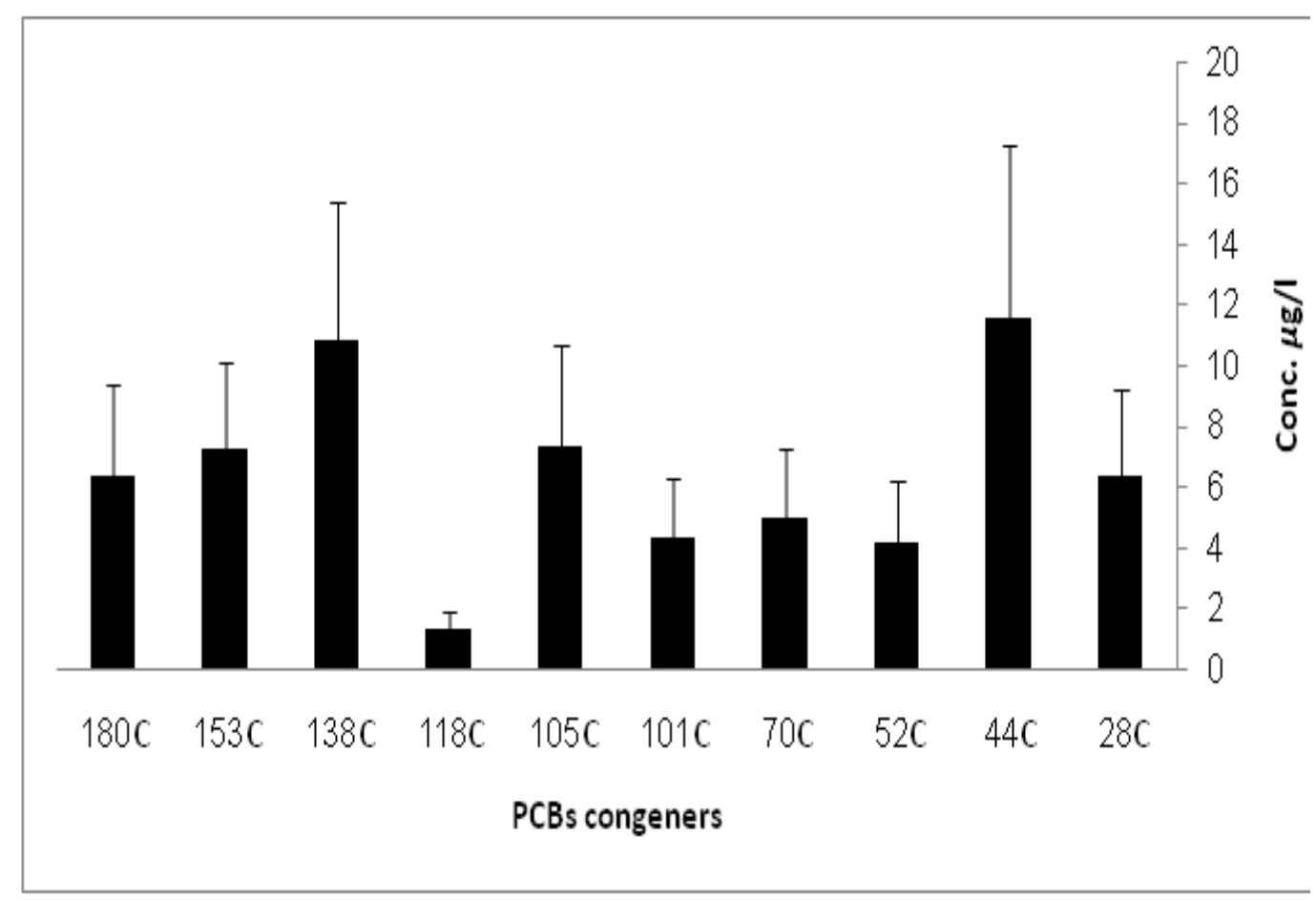

Each column and vertical bar represents mean values and SD, respectively

Fig.2.Total average concentration values of individual selected PCB congeners along at the sampling sites along Nile River. 


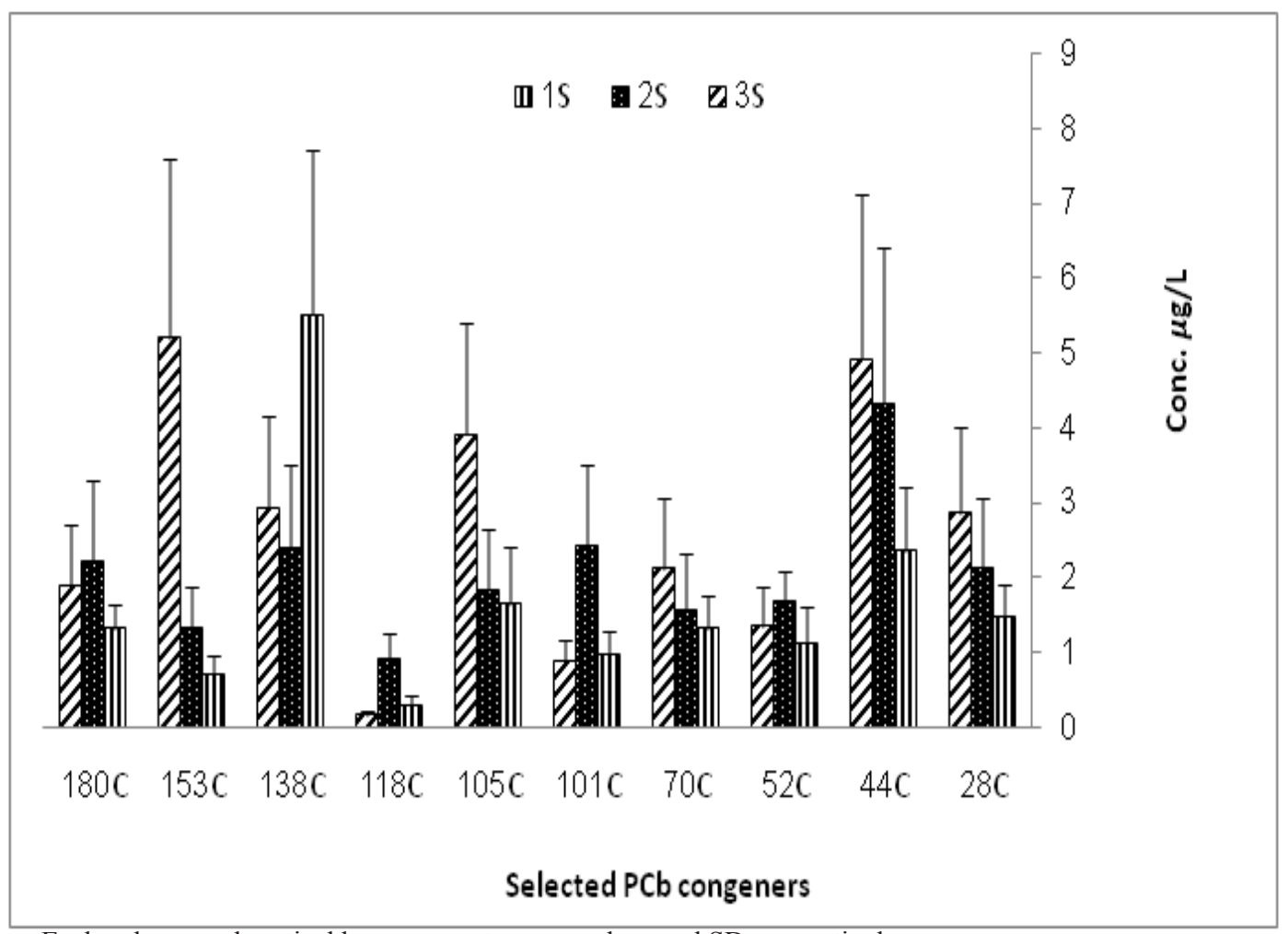

Each column and vertical bar represents mean values and SD, respectively

Fig.3. Distribution of average concentration values of the selected PCB congeners along at the sampling sites along Nile River.

from south to north of Nile River. S3 showed the higher concentration levels of PCBs congeners followed by $\mathrm{S} 2$ and the lowest concentrations were detected at S1. The individual PCBs concentrations showed that $\mathrm{C} 138$ recorded the highest level at S1, C44 was the highest at S2 and C153 showed the highest concentration at S3. All the recorded results of PCBs concentration levels were all above the permissible limits of drinking water indicated that Nile River water is not safe enough and may pose a health risk to human and aquatic environment. Therefore applying the counter measures for PCBs contamination and environmental laws enforcement are highly recommended to minimize the bad environmental impacts on biota and populations as well.

\section{References}

1. Williamson S, Ball A. and Pretty J. Trends in pesticide use and drivers for safer pest management in four African countries. Crop Prot., 27,1327-34 (2008)

2. Peter O., Lin K.C., Karen, P. and Joe A. Persistent Organic Pollutants (POPs) and Human Health. Washington. World Federation of Public Health
Association Publications, 1-35 (2002)

3. Wahaab R. A. and Badawy M. I. Water quality assessment of the River Nile system: an overview. Biomedical and Environmental Sciences, 17, 87100 (2004)

4. Mansour, S. A., Persistent organic pollutants (POPs) in Africa: Egyptian scenario. Human and Experimental Toxicology, 28 (9), 531-566 (2009)

5. Bjermo, H., Darnerud P. O. and Lignell S. et al., Fish intake and breastfeeding time are associated with serum concentrations of organochlorines in a Swedish population. Environment International, 51, 88-96 (2013)

6. El Nemr, A., Said, T. O., Khaled, A., El Sikaily, A. and Abd-Allah, A. M. A., Polychlorinated biphenyls and chlorinated pesticides in mussels collected from the Egyptian Mediterranean Coast. Bulletin of Environmental Contamination and Toxicology, 71, 290-297 (2003)

7. Nassar H. F., Tang N., Toriba A., Abdel-Gawad F. Kh., Guerriero G., Basem S. M. and Hayakawa K., Environmental carcinogenic polycyclic 
aromatic hydrocarbons (PAHs): concentrations, sources and hazard effects. International Journal of Advanced Research (IJAR), 3(10), 511-524 (2015)

8. Mahmoud M. H., Hamouda S. A., Nassar F. H. and Mabrook F., Spatio-temporal variation and health risk assessment of selected metals in nile river water, Beni-Suef Governorate, Egypt. Research Journal of Pharmaceutical, Biological and Chemical Sciences (RJPBCS), 7(5), 25552567 (2016).

9. Batterman S., Chernyak S., Gouden Y., Hayes J., Robins T. and Chetty S., PCBs in air, soil and milk in industrialized and urban areas of KwaZuluNatal, South Africa. Environmental Pollution, 157, 654-663 (2009)

10. Meikle B. and Youngson C., "Hydrolysis Rate of Dowc 179 in Water". Dow Chemical Comp. Agric. Res. Rep. Gs-1154, Walnut Grove Greek, California, USA, 6 (1970)

11. Nassar F. H., Tang, N., Toriba A., Abdel-Gawad F. Kh. and Hayakawa K., Occurrence and Risk Assessment of Polycyclic Cyclic Aromatic Hydrocarbons (PAHs) and Their Nitro Derivatives (NPAHs) in Nile River and Esmailia Canal in Egypt. International Journal of Scientific and Engineering Research (IJSER). 6(8), 2229 - 5518 (2016).

12. APHA (American Public Health Association). "Standard methods for the examination of water and wastewater". New York: American Water Works Association (2005).

13. Wilde F. D., "National Field Manual for the Collection of Water- Quality Data Chapter A1. Preparations for Water Sampling, Handbooks for Water-Resources Investigations”, TWRI Book 9, US Geological Survey, Reston, Va, USA, (2005).

14. Khaled A., El Nemr A., Said T. O., El-Sikaily A. and Abd-Alla A. M. A., Polychlorinated biphenyls and chlorinated pesticides in mussels from the Egyptian Red Sea coast. Chemosphere, 54(10), 1407-1412 (2004)

15. United States Environmental Protection Agency (USEPA), "Guidelines for Carcinogen Risk Assessment, PA/630/P-03/001F, United States Environmental Protection Agency (USEPA)", Washington, DC, USA, (2005).

16. Megahed, A. M., Dahshan, H., Abd-El-Kader, A. M., Mohamed, A.M., Elbana, M.H., Nabawy, E. and Mahmoud, H., Polychlorinated Biphenyls
Water Pollution along the River Nile, Egypt. The Scientific World Journal, 7, 1-7 (2015)

17. Dahshan, H., Megahed, A. M., Abd-El-Kader, A. M., Mohamed, A.M., Elbana, M.H., Nabawy, E. and Mahmoud, H., Polychlorinated Biphenyls Water Pollution along the River Nile, Egypt. Journal of Environmental Health science and Engineering, 14, 1-9 (2016)

18. Abdel-Dayem S., "Water quality issues in Egypt," in Proceedings of the Italian-Egyptian StudyDays on the Environment (IESDE '94), pp. 81-92, Cairo, Egypt, October (1994).

19. United States Environmental Protection Agency (USEPA), "National Primary Drinking Water Regulations, United States Environmental Protection Agency (USEPA)", Washington, DC,USA, (2009).

20. United States Environmental Protection Agency (USEPA), "Provisional Guidance for Quantitative Risk Assessment of PAH, EPA/600/R-93/089, United States Environmental Protection Agency (USEPA)",Washington, DC, USA, (1993).

(Received 20/10/2017; accepted $19 / 11 / 2017)$ 
رصد وتقييم المخاطر الناجمه عن وجود بعض من متجانسات المبيدات الحشريه المختارة في مياه نهر النيل، مصر

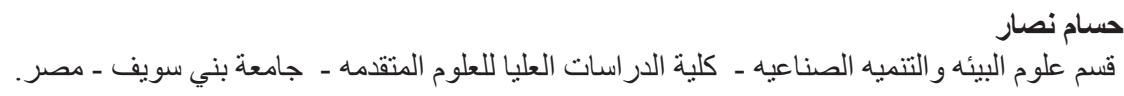

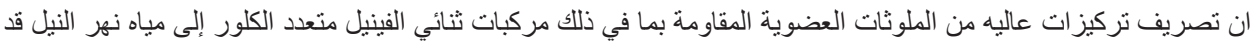

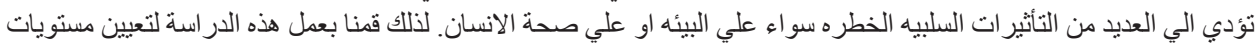

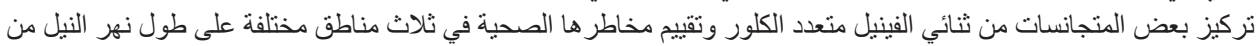

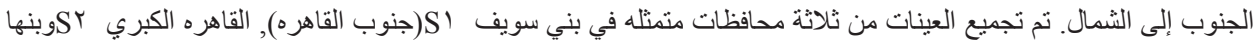

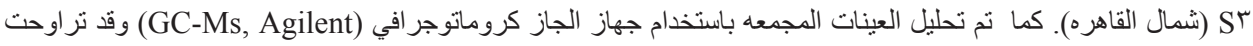

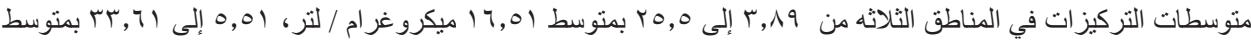

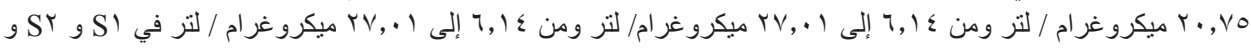

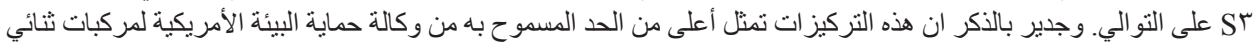

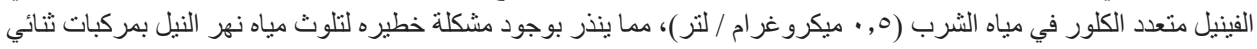

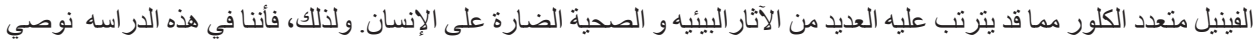

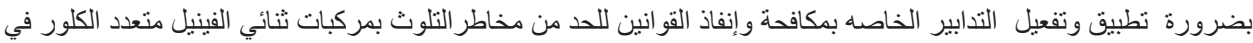

